\title{
Designing of Autonomous Wheelchair for Movement in Standing Position
}

\author{
J S Kalra, Rajesh Pant, Pankaj Negi, Vijay Kumar
}

\begin{abstract}
Driving a manual wheelchair on any surface is a difficult task and past invented automatic wheelchairs are available at a very high cost in the market. The purpose of this paper, work is to propose an autonomous wheelchair that will reduce human effort while moving on a surface with inclination or declination and is available at a comparatively lower cost. One of the basic problems of user on manual wheelchair is to overcome barriers like kerb, rough surfaces, inaccessible surfaces etc. Though many research have been done in this field, but the question of overcoming these barriers always remains as a topic of discussion for many researchers. In our paper a motor operated \& electronically hand controlled autonomous wheelchair concept which can overcome the architectural barriers to a considerable extent has been developed. This paper involves the design of an ergonomically designed battery powered wheelchair for multipurpose use. All the design parameters of wheelchair's are based on the standard design of stair in India. Major part of the paper focuses on the proposed design concept and mechanism and concludes by focusing upon the physical working model developed for the proposed design solution.
\end{abstract}

Keywords: electronically, physical working model, ergonomically designed.

\section{INTRODUCTION}

Wheelchair is an assisting device basically used for physically challenged people, having difficulty in moving from one place to another. There are lot of variety available in the market, and each and every model has its own pros and cons. Most easily and cheaply available devices are the manually operated and can only be used for moving from one place to another manually, but if a person wishes to stand on his/her position and move in standing position this option is not available in any kind of wheelchair. The available types of wheelchairs are:

Revised Manuscript Received on September 25, 2019.

J S Kalra1, Assistant professor, Department of Mechanical Engineering, Graphic Era Hill University, Dehradun, India.

Rajesh Pant, Assistant professor, Department of Mechanical

Engineering, Graphic Era Hill University, Dehradun, India.

Pankaj Negi, Research Scholar, Department of Mechanical Engineering,

Graphic Era University, Dehradun, India.

Dr Vijay Kumar, Professor, Department of Allied, Graphic Era Hill

University, Dehradun, India.

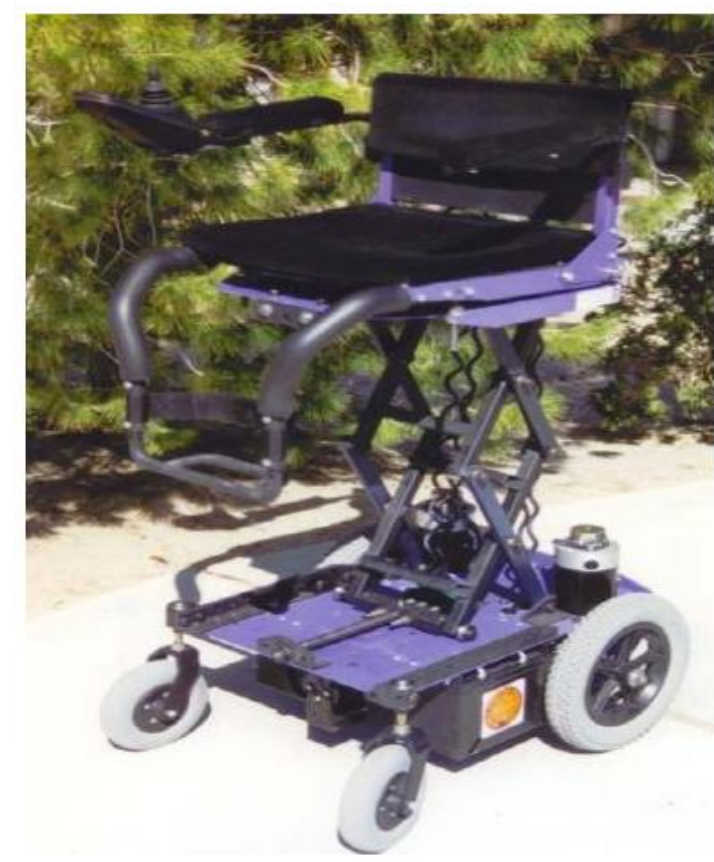

Fig 1: power elevating wheelchair

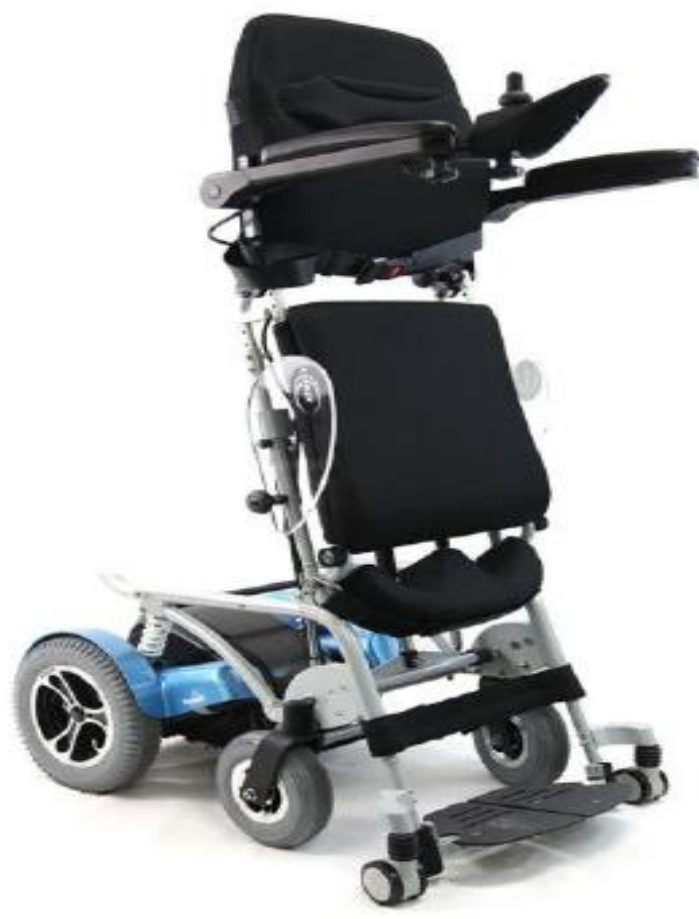

Fig 2: Power standing wheelchair

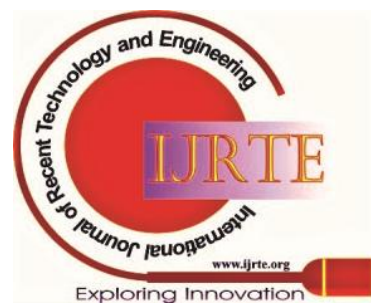




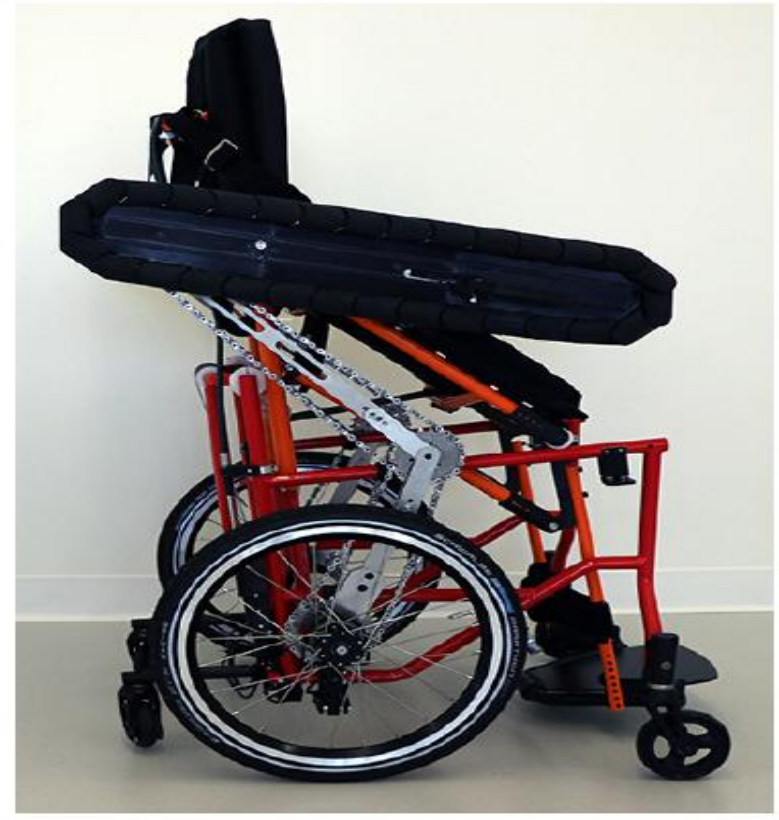

Fig 3: Manual standing wheelchair

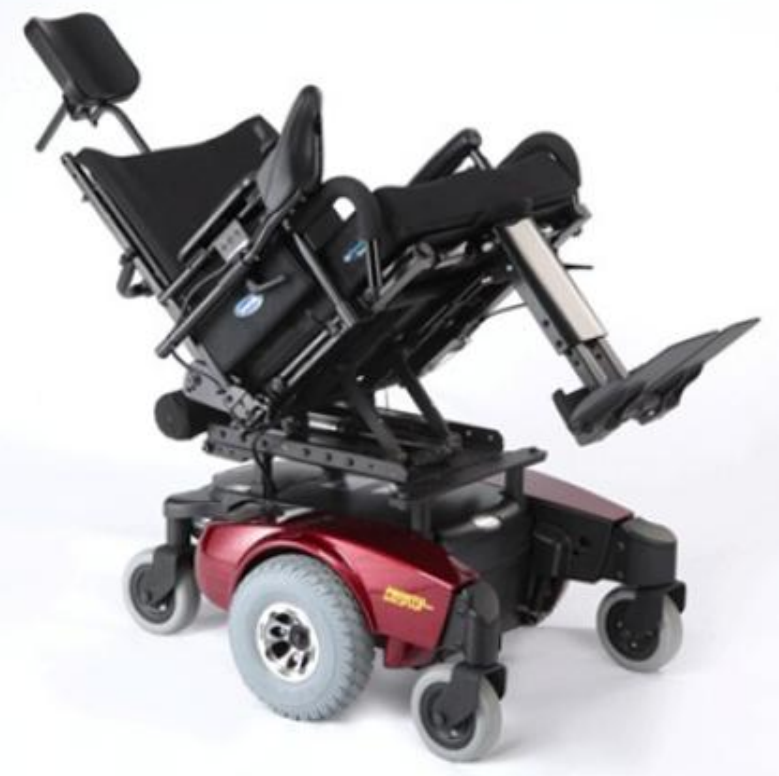

Fig 4: Power tilting wheelchair

Thus, looking at this drawback this paper proposes a new and unique design to overcome the stated problem. The paper titled that we have is autonomous wheelchair. This project helps the disabled people to stand through the support of the wheelchair and to move forward accordingly.

\section{Limitations of existing design:}

- $\quad$ High Level of Strength Require.

- You Need to Rely On Someone To Push The Chair.

- Cannot Use It for Longer Distance Movements.

- Get bogged/stuck easily in long grass and mud.

- Strained muscles.

- Bone density decreases.

- Blood pressure is almost always out whack.

- Lack of blood circulation can lead to blood clots.

- No self-body temperature regulation.

- Heights become absurdly scary.

\section{PROPOSED SYSTEM}

Proposed system is an AUTONOMOUS WHEELCHAIR, through our design the person can control \& maneuver the wheelchair easily through the use of one signal to the joystick. The controlling of joystick is quite handy because to move on has to direct it accordingly, to his/her desired motion.

Our designed wheelchair has the following advantages:

$>$ Quick and Easy Maneuver.

$>$ Height Adjustment.

$>$ Stoppage of Accidental Rolling.

$>$ Having the user as the controller. The user controls the speed and the direction the power wheelchair goes even.

All the manual difficulties in managing the Wheelchair have been rectified by analyzing the system thoroughly.

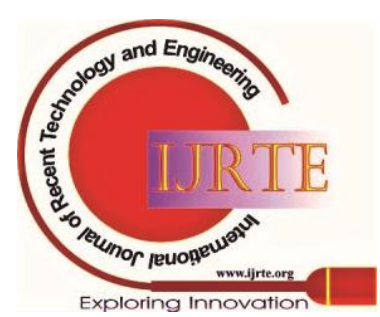




\section{METHODOLOGY}

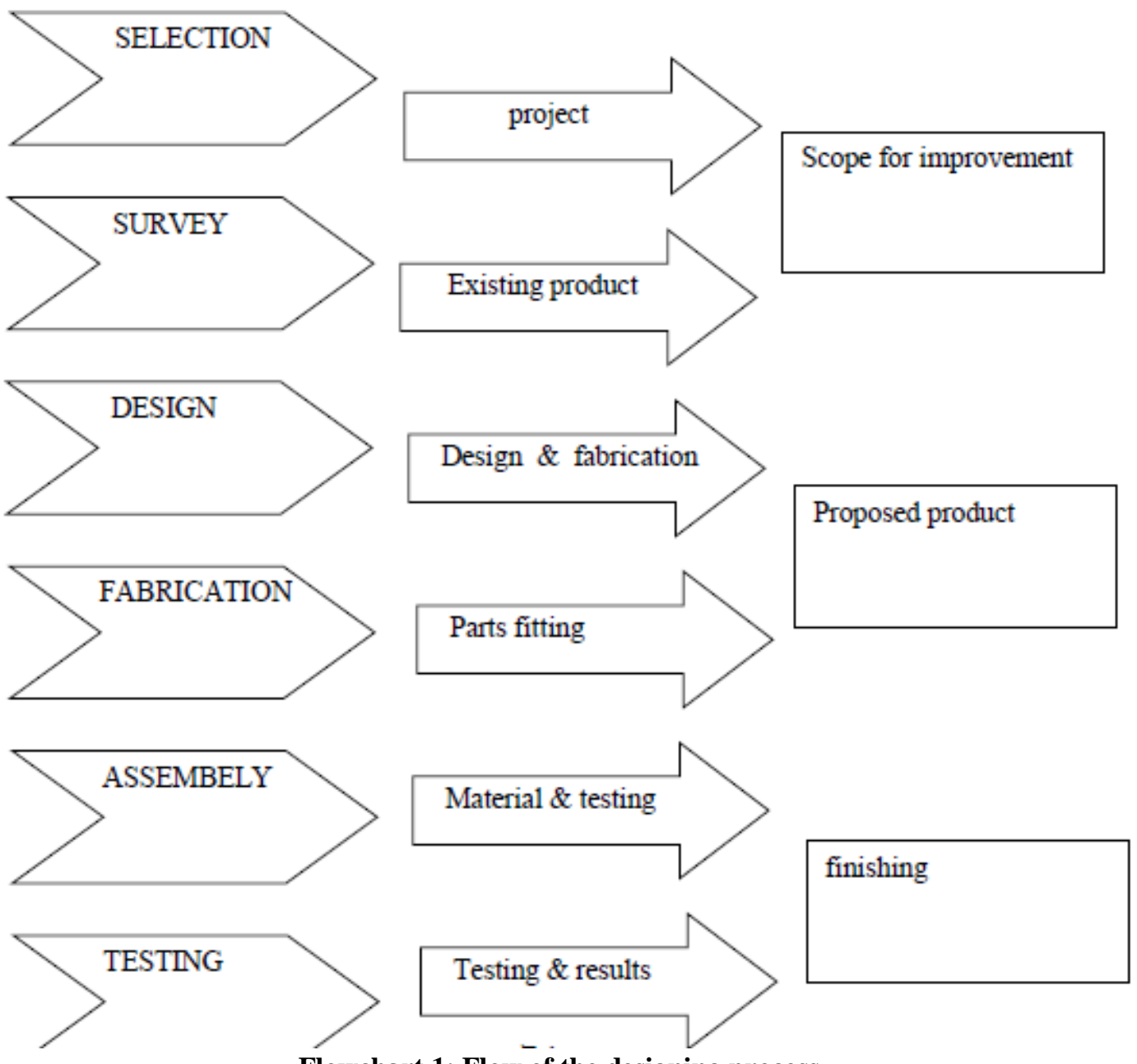

Flowchart 1: Flow of the designing process

\section{A. Principal Parts}

The wheelchair consists of following principal parts:

\section{B. Frame:}

A frame is a structural system that supports other components of a physical construction.

The frame is designed in solid works. This frame is fabricated using MS pipe of outer

width of $20 \mathrm{~mm}$. The weight of the frame is calculated to be $10.02 \mathrm{~kg}$. The legs of the

frame is connected to the shaft with the help of bushes, to which the motor is connected.

The frame forms a strong base for the person sitting on the wheelchair. 


\section{Designing of Autonomous Wheelchair for Movement in Standing Position}

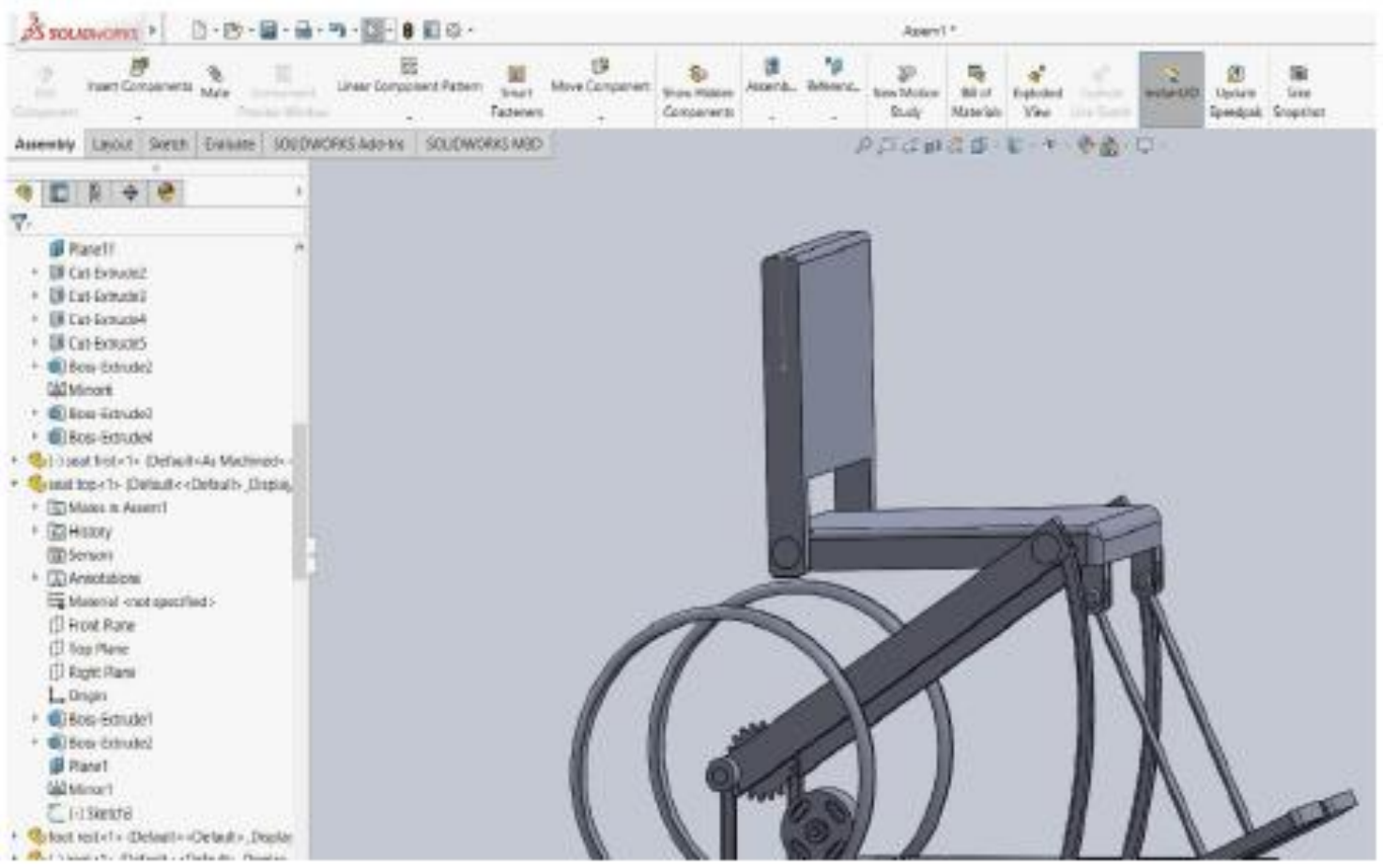

Fig 5: Wheelchair frame

\begin{tabular}{|c|c|}
\hline Properties & Value \\
\hline Density & $7850 \mathrm{~kg} / \mathrm{m} 3$ \\
\hline Young's modulus & $2 \times 105 \mathrm{MPA}$ \\
\hline Poison's ratio & 0.3 \\
\hline Bulk modulus & $1.66 \times 104 \mathrm{MPA}$ \\
\hline Shear modulus & $7.69 \times 104 \mathrm{MPA}$ \\
\hline Tensile yield strength & $250 \mathrm{MPA}$ \\
\hline Ultimate tensile strength & $250 \mathrm{MPA}$ \\
\hline Compressible yield strength & $750 \mathrm{MPA}$ \\
& \\
\hline
\end{tabular}

Table 1: Properties of the proposed material (mild steel)

\section{Wheels}

The front wheels are casters of 6 inch diameter and an overall height of $5 \mathrm{~cm}$ which are welded at the front legs of the frame. At the rear legs of the frame is connected a two tire mechanism on each side with the help of a shaft. The rear tires are made of rubber and have a diameter of 16 inch each. The tires on each side are connected together with the help of a solid shaft.

The required design is then made on solid works software which shows the connection of the tire mechanism with the frame. 


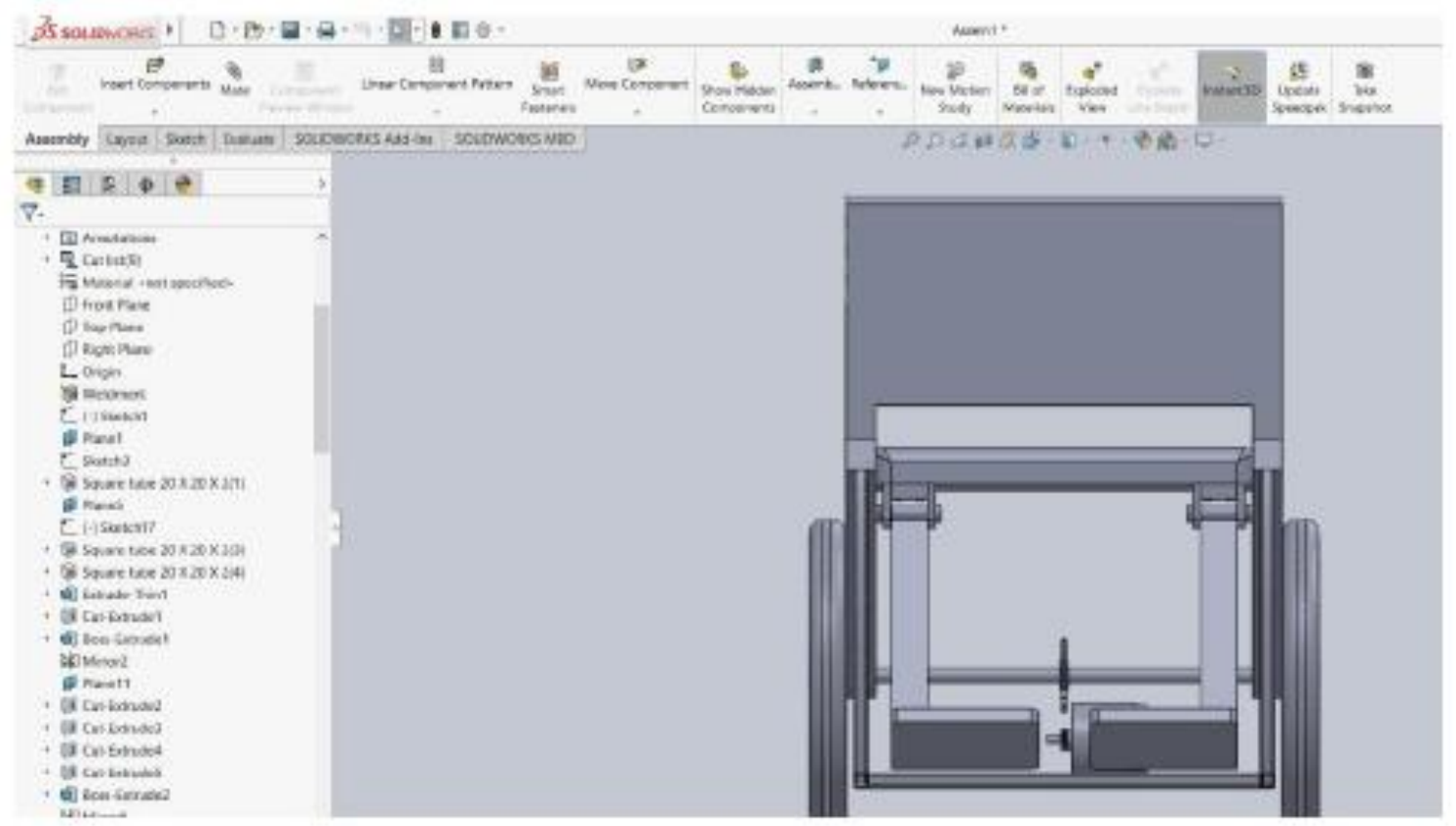

Fig 6: Design of wheels

\section{Motor and battery}

A geared motor is used as locomotion unit and this motion is transmitted to the wheels through shafts. This motor is mounted at the lower side of the frame and is connected to the shaft with the help of chain. A gear motor of $139.53 \mathrm{~N}$ $\mathrm{m}$ torque and $24 \mathrm{~V}$ is used.
Further the speed of the motor is reduced to suitable rpm using gearbox. The specification of the motor and the battery is shown in table 4.3 and 4.2 respectively. Two batteries of $12 \mathrm{~V}$ each are connected in series to provide 24 $\mathrm{V}$ to the motor. Batteries are also clamped at the lower side of the frame.

Table 2: Specification of the Motor

\begin{tabular}{|c|c|}
\hline Parameter & Specification \\
\hline Voltage & $24 \mathrm{~V}$ \\
\hline Current & $7 \mathrm{~A}$ \\
\hline Torque & $139.53 \mathrm{~N}-\mathrm{m}$ \\
\hline Speed & $30 \mathrm{rpm}$ \\
\hline
\end{tabular}

Table 3: Specification of the Battery

\begin{tabular}{|c|c|}
\hline Parameter & Specification \\
\hline Voltage & $12 \mathrm{~V}$ (each) \\
\hline Current & $7 \mathrm{~A}-\mathrm{h}$ \\
\hline
\end{tabular}




\section{Designing of Autonomous Wheelchair for Movement in Standing Position}

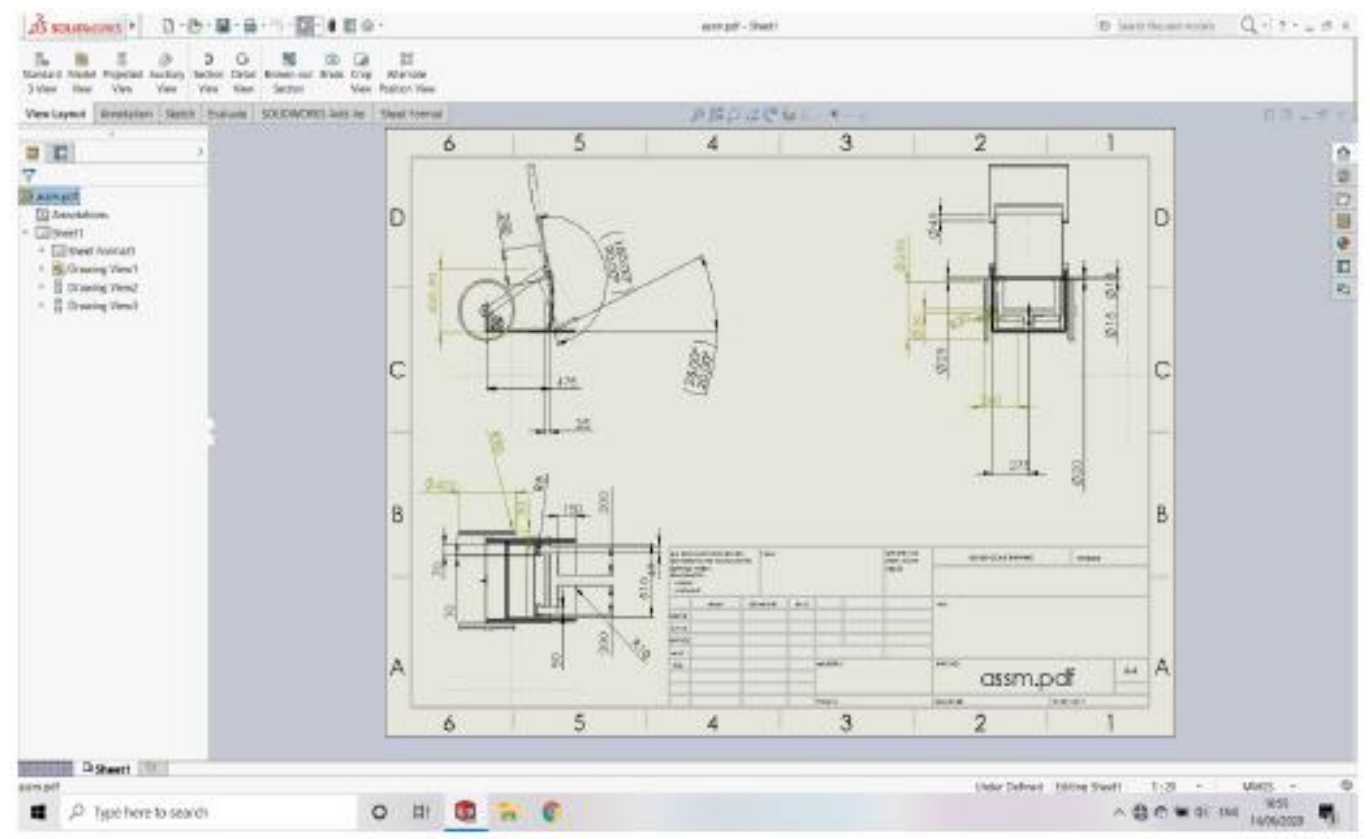

Fig 7: Draft of the proposed design

\section{E. Assembly and Fabrication}

The hollow pipes were cut into required lengths and welded properly in correct positions

to make the, frame. The plywood was cut to make the seat and back support. The shaft

was machined to fit as per requirement. The hubs were machined, and holes were drilled

so as to bolt the sprocket into place.

the parts were fitted as follows,

$>$ The shaft was held to the frame with the help of bushes.

$>$ The hub was fitted on the shafts and the wheels were fitted.

$>$ The motor and the battery were connected, and the motor was connected to the wheel with the help of chain and sprocket.

$>$ The transmission from the motor to the shaft was made with help of chains.

$>$ The wiring for the motor and the battery were made.

\section{WORKING PRINCIPLE}

The power is generated using a DC geared motor. This motor is coupled with a gear box. Due to this the high speed, low torque input of the motor gets converted to low speed high torque output. The geared box is coupled with the center shaft which gets high torque but low rpm. In the system the sprockets are of 33 teeth, 2 sprockets are mounted on the motor and shaft. The front and rear sprockets receive same high torque and are connected with the help of a chain. Since the sprocket on the front and rear shaft are same there will be no change in the torque transmitted and also the speed will remain same as the shaft. Two sprockets are used. Both the sprockets have 18 teeth. The DC gear motor will transmit the torque from one sprocket connected to the motor to the other sprocket at the shaft with the help of chain. As the shaft receives the required torque it starts to rotate the three-wheel mechanism

with the same speed as that of the motor the three heels are thus forced to rotate on the stairs and make the wheelchair move. One person will hold the wheelchair from the back for safety purpose.

\section{CALCULATIONS}

To calculate the force required to move the chair,

We will find force first,

Since

Force $=$ mass $\mathrm{x}$ acceleration due to gravity where $\{\mathrm{g}=$ acceleration due to gravity, i.e $9.81 \mathrm{~m} / \mathrm{s} 2\}$

Let the mass be $=$ mass of the body + mass of the system, i.e $=40 \mathrm{~kg}+30 \mathrm{~kg} \ldots \ldots . . \mathrm{i} . \mathrm{e}=70 \mathrm{~kg}$

Force $=70 \mathrm{~kg} \times 9.81 \mathrm{~m} / \mathrm{s} 2$

$\mathrm{F}=686.7 \mathrm{~N}-\mathrm{m}$

Diameter of the rear tire is $=16$ inch. i.e $40.64 \mathrm{~cm}$

In order to find the torque,

Torque $=$ Force $\mathrm{x}$ Radius

$\mathrm{T}=686.7 \mathrm{~N}-\mathrm{m} \times(0.4064 \div 2)$

$\mathrm{T}=139.53 \mathrm{~N}-\mathrm{m}$

\section{FUTURE SCOPE}

- The frame weight can be reduced by using high strength lightweight materials such as

composites, carbon fiber.

- The wheelchair can be automated by using electronics so that it will automatically sense

using the motion of the iris \& hand gestures.

- More heavy motor and battery can be used to lift loads more than $100 \mathrm{~kg}$.

- The backrest of the chair can be made adjustable by tilting it at different angles.

\section{REFERENCES}

1. M. A. (2006, Oct. 01). Professor Ernesto Blanco: A Lesson in Creative Engineering. Available:

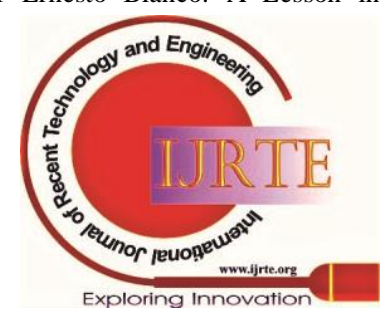


http://mitadmissions.org/blogs/entry/

2. Manuscale.(2013,0ct.01).'United Spinal' Techguide. Available: htto://www .usatechguide.org/itemreview.php?itemid $=1612$

3. S. Sharma. (2012, 0ct.01). Vardaan: stair climbing wheelchair Available: http://www.techped ia.in/award/proj ectdetailNARDAAN-A-Convertible-Manual- Stair-Climb ingWheelchair

4. I. Nayar. (2012,oct.02). Wherethe pedal meets the mettle.Available: http://photo.outlookindia.com/imnes/callerv/20120612/wheelchair iit k 20120625.ipg

5. S. S. f. E. B. a. Innovation. (2008, Oct. 01). The first manual stairclimbing wheelchair inthe world. Available: http://www.enterpriseeuropenetwork. ch/marketplace/index.php?file=bbsshow.php\&bbsref $=08 \% 020 \mathrm{CZ} \% 20$ $0746 \% 200 I$ RD

6. T. S. d. Liberta. (Oct. 14). Scoiattolo 2000. Available: http://www.tgr.it/

7. Y. Sugahara, N. Yonezawa, and K. Kosuge, "A novel stair-climbing wheelchair with transformable wheeled four-bar linkages," in IntelligentRobots and Systems (IROS), IEEE/ IEEE/ RSJ International Conference on, 2010, pp. 3333-3339.

8. TGR. (2009, Oct. 01). Scoiattolo 2000/E. Available: https://www.youtube.com/watch?v=Pm0695001Y8 